\title{
Silicon Carbide-Based Hydrogen and Hydrocarbon Gas Detection
}

Gary W. Hunter, Philip G. Neudeck, and Liang-Yu Chen

Lewis Research Center

Cleveland, Ohio

D. Knight

Cortez III Service Corporation

Cleveland, Ohio

C.C. Liu and Q.H. Wu

Case Western Reserve University

Cleveland, Ohio

Prepared for the

31st Joint Propulsion Conference and Exhibit

cosponsored by AIAA, ASME, SAE, and ASEE

San Diego, California, July 10-12, 1995

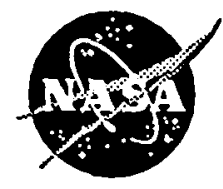

National Aeronautics and

Space Administration

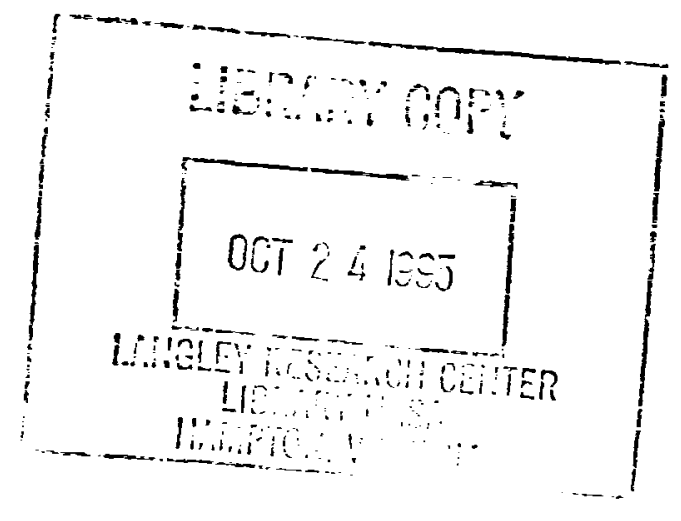




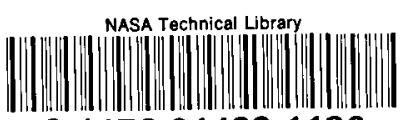

31176014231139

\title{
SLICON CARBIDE-BASED HYDROGEN AND HYDROCARBON GAS DETECTION
}

\author{
Gary W. Hunter, Philip G. Neudeck, and Liang-Yu Chen \\ NASA Lewis Research Center \\ Cleveland, OH 44135 \\ Dak Knight \\ Cortez/NASA Lewis Research Center \\ Cleveland, OH 44135 \\ C. C. Liu and Q. H. Wu \\ Electronics Design Center, Case Western Reserve University \\ Cleveland, OH 44106
}

\begin{abstract}
Hydrogen and hydrocarbon detection in aeronautical applications is important for reasons of safety and emissions control. The use of silicon carbide as a semiconductor in a metal-semiconductor or metal-insulator-semiconductor structure opens opportunities to measure hydrogen and hydrocarbons in high temperature environments beyond the capabilities of silicon-based devices. The purpose of this paper is to explore the response and stability of Pd-SiC Schottky diodes as gas sensors in the temperature range from $100{ }^{\circ} \mathrm{C}$ to $400^{\circ} \mathrm{C}$. The effect of heat treating on the diode properties as measured at $100^{\circ} \mathrm{C}$ is explored. Subsequent operation at $400^{\circ} \mathrm{C}$ demonstrates the diode's sensitivity to hydrogen and hydrocarbons. It is concluded that the Pd-SiC Schottky diode has potential as a hydrogen and hydrocarbon sensor over a wide range of temperatures but further studies are necessary to determine the diode's long term stability.
\end{abstract}

\section{INTRODUCTION}

Detection of hydrogen and hydrocarbons over a wide range of concentrations is important for a number of aeronautical and commercial applications. This is due to their use both as a fuel and their presence as a by-product of the use of fuels. Monitoring of flammable or explosive concentrations of these gases is necessary in their safe use, storage and handling. Detection of low concentrations of these gases is a vital issue in controlling and monitoring emissions from, for example, an aircraft engine. NASA Lewis Research Center (LeRC), in conjunction with Case Western Reserve University (CWRU), has been developing hydrogen and hydrocarbon sensor technologies intended to meet a wide variety of needs. One component of this program is the development of gas sensor technology using silicon carbide $(\mathrm{SiC})$ as a semiconductor in Metal-Insulator-Semiconductor (MIS) or Metal Semiconductor (MS) sensors. This work adapts previously developed silicon-based hydrogen sensing technology to SiC.

There are significant advantages in a number of gas sensing applications to the use of $\mathrm{SiC}$ as the semiconductor rather than silicon (Si). These advantages are due to the improved material properties of $\mathrm{SiC}$ over $\mathrm{Si}$ such as high temperature semiconductor operation, superior mechanical toughness, and increased thermal conductivity. For example, the recovery back to its baseline after exposure to hydrogen of a sensor operated at near room temperature can be slow in an inert environment. ${ }^{1}$ This recovery time could be greatly accelerated by heating the sensor to high temperatures without damage to the sensor. Further, detection of gases such as hydrocarbons, which decompose at high temperatures, could be facilitated by heating the sensor to the gas decomposition temperature.

Recently, the capabilities of gas sensors using $\mathrm{SiC}$ have been explored. Schottky diodes composed of palladium (Pd) and palladium-silver (PdAg) deposited on SiC have been shown to be sensitive to $5000 \mathrm{ppm}$ hydrogen in helium or nitrogen at near room temperature. ${ }^{1-2}$ SiC-based capacitors using 
platinum (Pt) as the gas sensitive metal have detected hydrogen concentrations as low as $2.5 \mathrm{ppm}$ and have operated at temperatures as high as $\mathbf{8 0 0}$ ${ }^{\circ} \mathrm{C}{ }^{3}$ Further, sensitivity to hydrocarbons such as methane, ethane, and propane at $457^{\circ} \mathrm{C}$ has been demonstrated. ${ }^{4}$ MIS SiC-based structures using several different types of contacts have, with varying sensitivities, measured hydrogen at temperatures from near room temperature to $627^{\circ} \mathrm{C} .^{3}$ Fabrication of a complete SiC-based sensor with temperature detector and heater has been attempted with mired results. ${ }^{1}$

A possible mechanism for hydrogen and hydrocarbon detection in SiC-based devices using Pd is the same as that proposed for $\mathrm{Pd} / \mathrm{Si}$-based devices: the dissociation of hydrogen or hydrocarbons on the metal surface leads to the formation of a dipole layer composed of hydrogen at the metal-semiconductor or metal-insulator interface. This dipole layer affects the electronic properties of the device in proportion to the amount of hydrogen and other gas species (especially orygen) present in the surrounding ambient atmosphere. ${ }^{67}$

NASA LeRC and CWRU are presently developing a complete hydrogen and hydrocarbon gas sensor to be operational to temperatures of at least $400^{\circ} \mathrm{C}$. This effort involves two major components. One component is the fabrication of a stable gas sensing element which can withstand high temperature operation and be sensitive to hydrogen bearing gases in a variety of ambients. The sensing element will use Pd or a Pd-alloy as the hydrogen or hydrocarbon sensitive metal The first structure being examined is a Pd-SiC Schottky diode. The second major component in the $\mathrm{SiC}$ sensor development program is the fabrication of a complete sensor package which can monitor and control the temperature of the hydrogen or hydrocarbon sensing element.

This paper discusses the progress of SiC-based hydrogen and hydrocarbon sensor development at NASA LeRC and CWRU. We will first discuss the fabrication and testing of the Pd-SiC Schottky diode sensing elements. We will then focus on two elements of the characterization of the diodes: 1) Effects of heat treatments on diode operation at $\mathbf{1 0 0}$ ${ }^{\circ} \mathrm{C}$. 2) Sensor operation at $400^{\circ} \mathrm{C}$. It is shown that Pd-SiC Schottky diodes can detect hydrogen at 100 ${ }^{\circ} \mathrm{C}$ even after a range of heat treatments, and at $400^{\circ} \mathrm{C}$. Hydrocarbon detection, specifically propylene, is also demonstrated at $400^{\circ} \mathrm{C}$. We will then discuss the present development at CWRU of a complete sensor package. The development of a complete sensor package for high temperature operation involves different processing than a room temperature sensor package. In conclusion, this technology shows promise for aeronautical applications although further development is necessary.

\section{DEVICE FABRICATION AND TESTING}

Palladium MS Schottky diodes with $\mathrm{SiC}$ as the semiconductor were prepared in the following manner. An 4-5 $\mu \mathrm{m}$ thick 4H-SiC epilayer was grown by chemical vapor deposition on a commercially available $4 \mathrm{H}$ silicon-face SiC substrate. ${ }^{29}$ Approximately 400 angstroms of palladium metal were sputter deposited onto the as-grown $4 \mathrm{H}-\mathrm{SiC}$ epilayer surface and patterned by a lift-off technique into circular Pd Schottky patterns of diameter $200 \mu \mathrm{m}$. Device fabrication was completed by sputtering Pd onto the bottom of the wafer to form a backside contact.

The facility used for sensor testing at NASA LeRC is shown schematically in Figure 1 . The facility can supply a continuous flow of gaseous hydrogen $\left(\mathrm{H}_{2}\right)$, helium $(\mathrm{He})$, nitrogen $\left(\mathrm{N}_{2}\right)$, or air, either individually or as a mixture, to a chamber containing the sensor under test. The temperature (T) and pressure $(P)$ of the gas are measured as the gas enters the test chamber. The composition of the gas is monitored by a mass spectrometer. The gas leaves the test chamber and is sent through a flame before being vented.

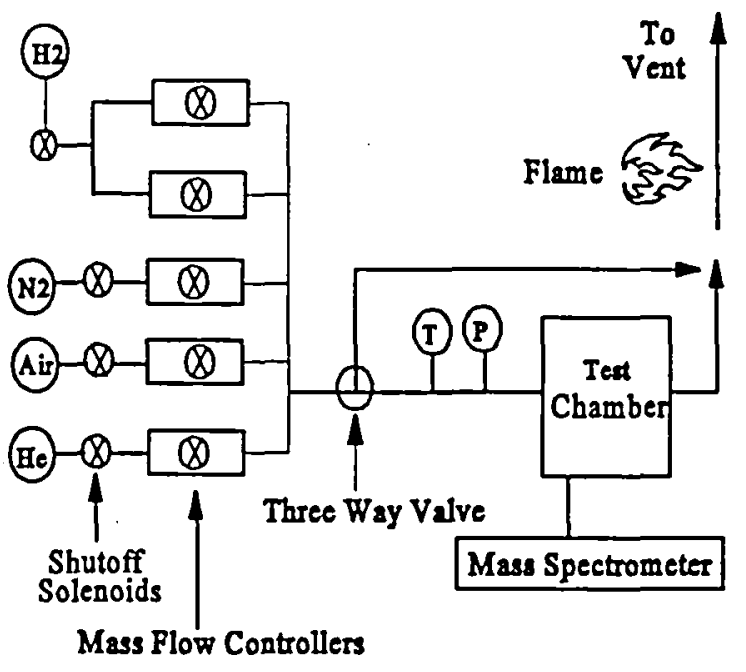

Figure 1. Schematic diagram of the NASA LeRC $\mathrm{H}_{2}$ sensor testing facility. $T$ and $P$ represent temperature and pressure measurements. 
Computer-controlled mass flow controllers accurately control gas flow into the test chamber. The helium, nitrogen, and air mass flow controllers are calibrated for flows from 0 to 1000 standard cubic centimeters per minute $(\mathrm{sccm})$. One hydrogen mass flow controller operates in the range from 0 to $20 \mathrm{sccm}$ and a separate hydrogen flow controller operates from 20 to $1000 \mathrm{sccm}$. A three-way valve allows the gas to bypass the test chamber and go directly to the vent. This feature allows the mass flow controllers to be stabilized without flowing gases through the test chamber.

The mass spectrometer provides an independent measure of the gases flowing into the system and the relative concentration of the gases in the test chambers as a function of time. This information, accounting for the time delay inherent in the mass spectrometer reading, has been used to determine the amount of time for changes in the flow composition to reach a steady state value in the test chamber. The time it takes to reach steady state affects the corresponding measured response and recovery times of the sensor. The total flow was kept constant at $1000 \mathrm{sccm}$. Under these conditions, the time for steady state in the chamber used in the tests discussed in this paper is usually less than $\mathbf{4}$ minutes.

The Pd-SiC Schottky diodes were characterized in a test chamber containing a probing station and a heated sample stage. The $\mathrm{SiC}$ substrate rested on a gold-covered alumina substrate so that the Pdcovered backside of the chip made contact with the gold. Sample contact was made using tungsten probes. One probe made contact with the diode's patterned $\mathrm{Pd}$ surface while another probe made contact with the gold and thus the backside of the chip. The alumina substrate rested on the hot stage whose temperature was controlled from room temperature to $400^{\circ} \mathrm{C}$.

The electrical properties of the Pd-SiC Schottky diodes were determined using capacitance measurements. The response of the diode capacitance measured at $0 \mathrm{~V}$ with time $(C-t)$ was used to characterize the time dependent behavior of the system upon exposure to various gases. The barrier height of the diode was determined using capacitance-voltage (C-V) measurements by finding the intercept on the voltage axis of the plot $1 / C^{2}$ vs V. The barrier height of a diode is, in general, a measure of the semiconductor surface states and metal work function. Changes in the barrier height correspond to changes in the diode properties and operation. ${ }^{10}$ Corresponding current-time (I-t) and current-voltage (I-V) measurements were also taken in separate tests. The I-t and I-V results from these tests reinforce the results from the capacitance measurements but will not be discussed in detail here due to space limitations. However, as with the silicon-based devices ${ }^{1}$, the sensor will likely be operated in a mode that measures a change in current. Thus, the I-t data is presented to illustrate operational device behavior.

\section{RESULTS AND DISCUSSION}

The use of $P d$ in an electronic structure with $\mathrm{SiC}$ as the semiconductor for gas detection in aeronautical applications depends on the inherent stability of $\mathrm{Pd}$ and $\mathrm{SiC}$ in a wide range of temperatures and ambient gas environments. The simplest structure for such applications is a Pd-SiC Schottky diode. Although some interaction between Pd directly deposited on SiC is expected even at room temperature ${ }^{11}$, the effect this interaction has on the gas sensing capabilities of the Pd-SiC Schottky diode has not been explored. Further, it remains to be determined whether the gas sensing capabilities of a Pd-SiC Schottky diode are changed with heat treatment and if the properties of such a diode eventually reaches stable state after which no significant operational changes occur. If the diode properties drift with time, then a barrier layer may be necessary between the $\mathrm{Pd}$ and $\mathrm{SiC}$ to stabilize the diode. The thickness and type of barrier layer depends on the inherent stability of the Pd-SiC system. Thus, for future $\mathrm{Pd}$ with $\mathrm{SiC}$ gas sensor development, an understanding of the properties of the Pd-SiC diode system is necessary. Our testing of these diodes took place at $100^{\circ} \mathrm{C}$ and at $400^{\circ} \mathrm{C}$.

\section{Operation at $100^{\circ} \mathrm{C}$}

In order to explore the properties of the Pd-SiC Schottky diode system, we first sought to understand the effects of heat treating on diode operation at $100{ }^{\circ} \mathrm{C}$. A newly fabricated diode was first operated at $100^{\circ} \mathrm{C}$ to establish a baseline. The diode was then heated from $100^{\circ} \mathrm{C}$ to $200^{\circ} \mathrm{C}$ in air for 18 hours and back to $100{ }^{\circ} \mathrm{C}$ with no probe in contact with the Pd. After this cycle was completed, the probe contact with the $P d$ was then reestablished. The diode was then characterized at $100^{\circ} \mathrm{C}$ by exposure to differing ambient gases and measurement of its electronic properties. The pattern of gas exposure (Figure 2) was 10 minutes of air, 40 minutes of $\mathrm{He}, 40$ minutes of $\mathrm{He}+1000 \mathrm{ppm} \mathrm{H} \mathrm{H}_{2}\left(\mathrm{He} / \mathrm{H}_{2} \mathrm{mix}\right)$ 
followed by 10 minutes of He and 10 minutes of air. The initial air exposure establishes the baseline capacitance while the 40 minutes in helium examines the effect of removal of the oxygen on the diode behavior. Exposure to the $\mathrm{He} / \mathrm{H}_{2}$ mix illustrates the diode's response to low concentrations of hydrogen. The He and air exposures show the diode's recovery in inert environments and in air respectively. Measurements of the $C-V$ curves were taken in air and in $\mathrm{He}$ before the exposure to hydrogen, and while in the diode is in the $\mathrm{He} / \mathrm{H}_{2}$ mix. The same procedure of high temperature heat treatment in air for 18 hours followed by diode characterization at $100^{\circ} \mathrm{C}$ was repeated with heat treatments at $300^{\circ} \mathrm{C}$ in air and then at $400^{\circ} \mathrm{C}$ in air. The $\mathrm{C}$ - $t$ measurement as in Figure 2, with corresponding C-V measurements, were taken 3 times at $100^{\circ} \mathrm{C}$ and after the $200^{\circ} \mathrm{C}$ cycle, and 4 times after the $300^{\circ} \mathrm{C}$ and $400^{\circ} \mathrm{C}$ cycles. The response of the system is explored in Figures 2-5.

Figure 2 shows the $C$-t response to the differing gas ambients both before heat treating and after the final $400{ }^{\circ} \mathrm{C}$ heat treatment. The two curves are very similar with the major difference being a nearly $0.5 \mathrm{pF}$ decrease in the magnitude of the diode capacitance at zero bias with heat treating. The before curve shows no significant change in the diode capacitance in the oxygen-deficient $(\mathrm{He})$ environment while the after curve increases slightly (0.1 pF) above the air baseline in helium. Before heat treating, the capacitance increases in the presence of the $\mathrm{He} / \mathrm{H}_{2}$ mix by $1.8 \mathrm{pF}$ before becoming nearly constant. After heat treating, the capacitance peaks slightly before leveling off at nearly the same $1.8 \mathrm{pF}$ increase from the air baseline. The recovery time towards the baseline is more rapid in air than in $\mathrm{He}$ for both before and after heat treating curves. Thus, the heat treating shifts the baseline capacitance of the diode but does not change the qualitative response of the diode.

Figure 3 shows the plot of $1 / C^{2}$ vs $V$ from $-2 V$ to $0 \mathrm{~V}$ measured in air and in $\mathrm{He} / \mathrm{H}_{2}$ mix before and after heating treating. Both before and after heat treating, the curves in air are displaced but parallel from those taken while the diode is in the $\mathrm{He} / \mathrm{H}_{2}$ mix. The fact that the curves are parallel suggests that the major effect on the diode of the exposure to the $\mathrm{He} / \mathrm{H}_{2} \mathrm{mix}$ is to change the work function of the $\mathrm{Pd}$.

Comparison of the before and after heating air curves show there is an increase in the magnitude of $1 / C^{2}$ accompanied by nearly a $14 \%$ change in the slope of $1 / C^{2}$. The same is true for the before and

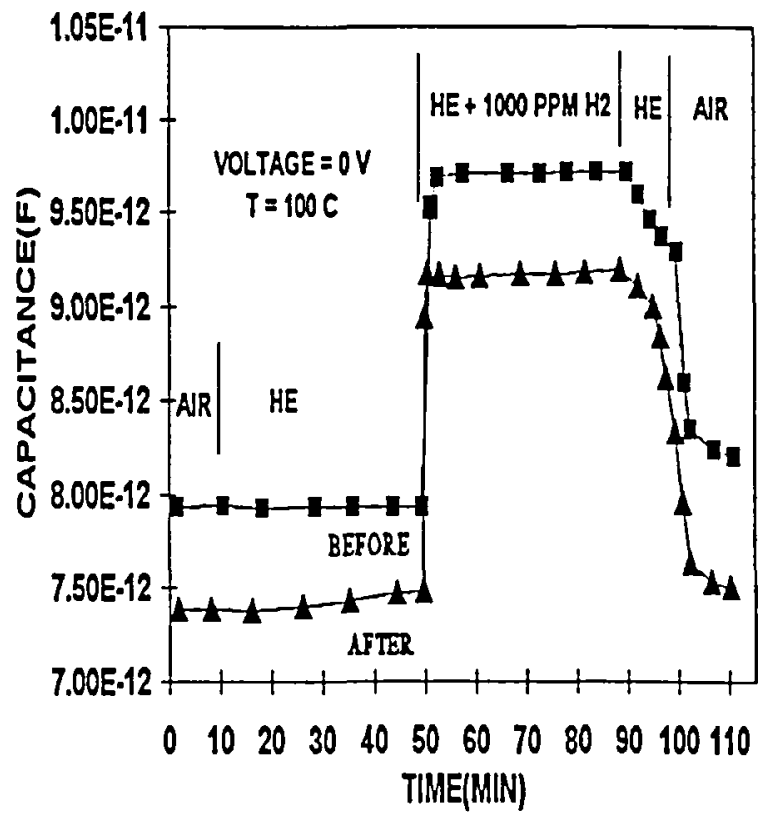

Figure 2. Capacitance at zero bias vs time at $100^{\circ} \mathrm{C}$ before heat treating $(\boldsymbol{\sigma})$ and after the final heat treatment to $400{ }^{\circ} \mathrm{C}(\Delta)$. The diode is exposed to air, $\mathrm{He}, \mathrm{He}+1000 \mathrm{ppm} \mathrm{H}$, then $\mathrm{He}$ and air. Heat treating does not significantly change the qualitative response of the diode.

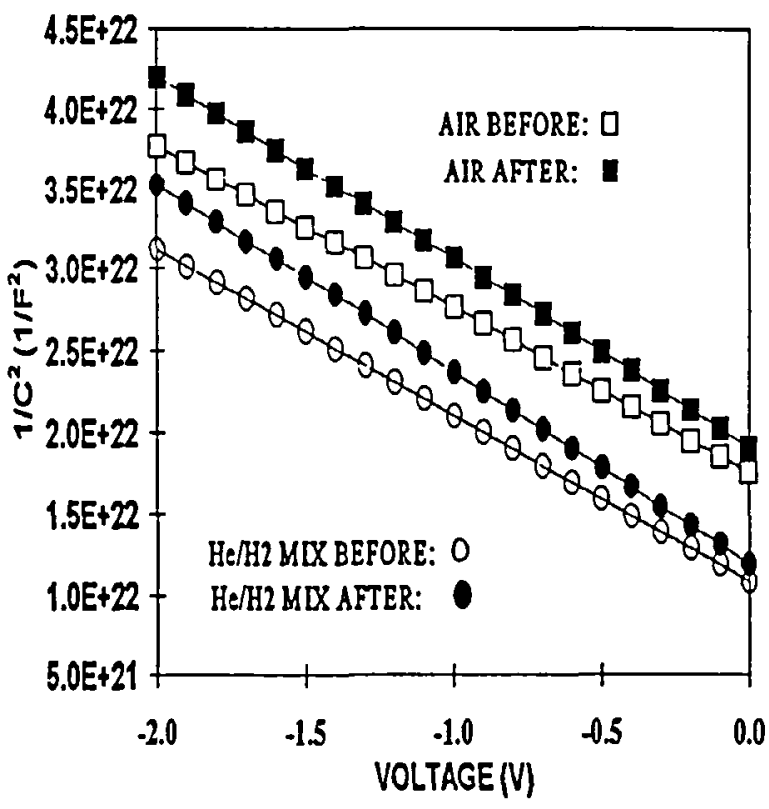

Figure 3. Plot of $1 / \mathrm{C}^{2}$ measured at $100{ }^{\circ} \mathrm{C}$ vs Voltage before heat treating in air ( $\square$ ) and $\mathrm{He}+1000 \mathrm{ppm} \mathrm{H}_{2}$ $(O)$ and after heat treating in air $(\square)$ and $\mathrm{He}+1000$ ppm $\mathrm{H}_{2}(\Theta)$. A change with heat treating is evident in both the magnitude of the capacitance and slope of $1 / C^{2}$. 
after $\mathrm{He} / \mathrm{H}_{2}$ mix curves. However, comparison of the before and after air barrier heights derived from Figure 3 show on average only around a $4 \%$ change. The same holds for the before and after $\mathrm{He} / \mathrm{H}_{2} \mathrm{mix}$ barrier heights. This change in magnitude and slope in the $1 / \mathrm{C}^{2}$ curve with a considerably less change in the corresponding barrier height may be due to trapping and detrapping of deep levels in the SiC.

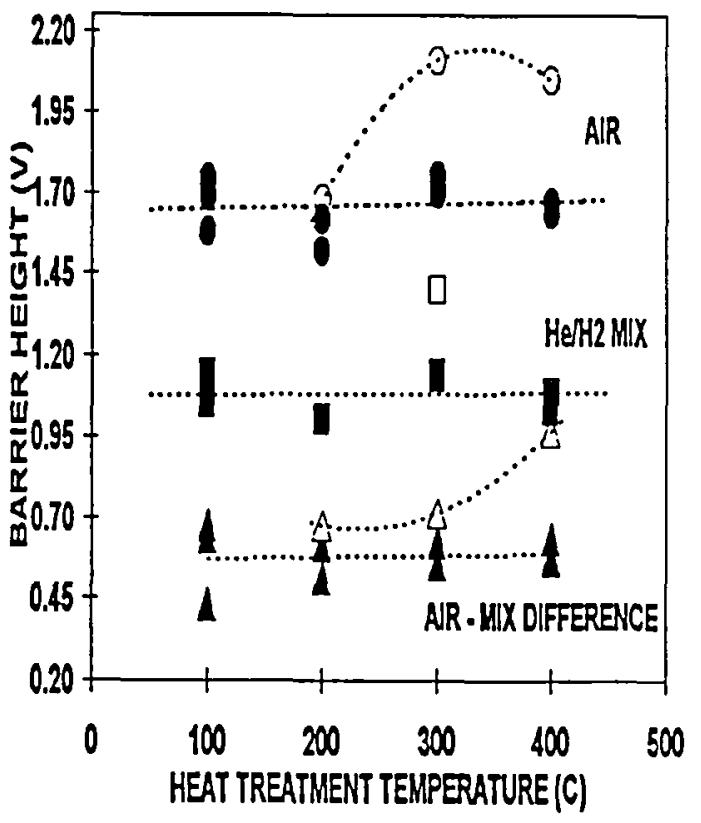

Figure 4. Barrier height measured at $100^{\circ} \mathrm{C}$ by $1 / C^{2}$ vs $\mathrm{V}$ measurements vs maximum heat treatment temperature. The open symbols are barrier heights first taken after air heat treatment: measured in air $(O)$, measured in $\mathrm{He}$ $+1000 \mathrm{ppm} \mathrm{H}_{2}(\square)$, and the difference between these two barrier heights $(\Delta)$. The closed symbols are the barrier heights taken subsequently: measured in air (O), measured in $\mathrm{He}+1000 \mathrm{ppm} \mathrm{H}_{2}(\mathrm{C})$, and the difference between these two barrier heights (A). The dotted lines are separate least squares fits through the closed and open symbols.

A summary of the results of the barrier height measurements for all temperatures and $\mathrm{C}-\mathrm{V}$ measurements is presented in Figure 4. Shown is the barrier height in air, in $\mathrm{He} / \mathrm{H}_{2}$ mix, and the difference between the air and $\mathrm{He}_{2} \mathrm{H}_{2}$ mix barrier heights. The data points at $100^{\circ} \mathrm{C}$ represent the initial values. The data points at 200,300 , and 400 represent the barriers heights measured at $100^{\circ} \mathrm{C}$ after temperature cycling to $200^{\circ} \mathrm{C}, 300^{\circ} \mathrm{C}$, and $400^{\circ} \mathrm{C}$ respectively. The first barrier heights measured after heat treating at a given temperature are denoted by open symbols while those measured in subsequent tests are denoted by closed symbols. The air-mix difference data is included in the figure to monitor whether there is pattern to the change in barrier height with exposure to hydrogen.

There are two points to note in Figure 4. First, at a given temperature, the barrier heights measured in the $\mathrm{He} / \mathrm{H}_{2}$ mix are generally consistent except for the first point taken after heat cycling at $300^{\circ} \mathrm{C}$. This $300^{\circ} \mathrm{C}$ point appears anomalous and will not be discussed in the subsequent discussion. At a given temperature, the maximum difference in $\mathrm{He} / \mathrm{H}_{2}$ mix barrier heights was at most $100 \mathrm{mV}$ and on average varied from the mean by $18 \mathrm{mV}$ out of a nearly a $1.1 \mathrm{~V}$ barrier height. In contrast, the air barrier height first measured after heat treating at a given temperature (open circles) is noticeably different from that measured in the subsequent tests (closed circles) especially after heat treating at $\mathbf{3 0 0}$ ${ }^{\circ} \mathrm{C}$ and $400^{\circ} \mathrm{C}$. These differences can be as high as $410 \mathrm{mV}$. The difference barrier height varied from $430 \mathrm{mV}$ to $970 \mathrm{mV}$ predominately due to the scatter in the air barrier height. This suggests that after heat treating, the diode in air is in a different state than it is after exposure to the $\mathrm{He} / \mathrm{H}_{2}$ mix.

Secondly, after the first exposure to hydrogen after heating, the subsequent barrier height measurements (closed symbols) do not show a discernable pattern with respect to heat treatments. For example, the barrier heights do not consistently drift upward with temperature cycling. The dotted lines in Figure 4 illustrate this point. The dotted lines are least square fits of the barrier heights as a function of the heat treating temperature. The barrier heights first measured in air are separately least squares fit from the barrier heights in air measured subsequently. The same is true for the least squares fit for the difference barrier heights. The dotted line associated with the $\mathrm{He} / \mathrm{H}_{2}$ mix includes all the points (except for the anomalous point measured at $\mathbf{3 0 0}$ $\left.{ }^{\circ} \mathrm{C}\right)$ with no distinction to order of measurement. Although the barrier heights in air first measured after heating show an increase after $200^{\circ} \mathrm{C}$, the fitting for the subsequently measured barrier heights in air is nearly a horizontal line with a slope on the order of $10^{-5} \mathrm{~V} /{ }^{\circ} \mathrm{C}$. Likewise, the slope of the dotted line for the $\mathrm{He} / \mathrm{H}_{2}$ mix barrier heights is also a horizontal line with a slope on the order of $10^{-5}$ $\mathrm{V} /{ }^{\circ} \mathrm{C}$. Thus, within the limits of this study, the long term diode structure as measured by the barrier 
height does not change drastically with heat treatment but rather seems to oscillate about a mean value.

Figure 5 shows a plot similar to Figure 4 except it is the capacitance at zero bias in air ( $)$, in the $\mathrm{He} / \mathrm{H}_{2}$ mix (D), and the difference between these two capacitances $(\Delta)$ that is plotted at each maximum heating temperature. The capacitance plotted is the capacitance near the time at which the $C-V$ curves are taken for the air and $\mathrm{He} / \mathrm{H}_{2}$ mix data. The dotted lines are meant to guide the eye for the air and $\mathrm{He} / \mathrm{H}_{2}$ mix capacitance while the solid line shows a linear least squares fitting of the difference in capacitance data. Further, this data does not include the first experiment performed after heating to a given temperature but only the data taken subsequently. This is done to emphasize the long term behavior of the system.

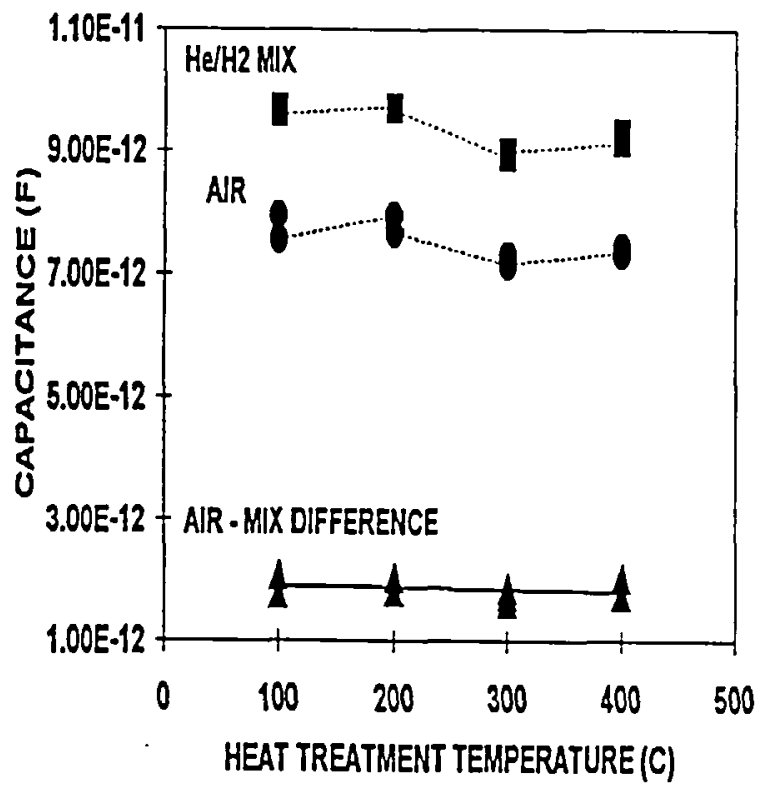

Figure 5. Capacitance at zero bias at $100^{\circ} \mathrm{C}$ vs maximum heat treatment temperature in air $(\theta)$, $\mathrm{He}+1000 \mathrm{ppm} \mathrm{H}_{2}\left({ }^{\prime}\right)$, and the difference between these two capacitances $(\Delta)$. The changes in capacitance in air with heat treating are paralleled by changes in the capacitance in the $\mathrm{He} / \mathrm{H}_{2}$ mix resulting in a difference between these two values which does not change significantly with heat treating.

It was noted in the discussion of Figure 2 that the capacitance dropped with heat treating but the change in capacitance between the air and $\mathrm{He} / \mathrm{H}_{2}$ mix values was nearly constant. This pattern is seen for all of the data in Figure 5. The air capacitance decreases with heat treating above $200^{\circ} \mathrm{C}$. However, the $\mathrm{He} / \mathrm{H}_{2}$ mix capacitance also decreases which results in no significant decrease in the airmix difference. The average difference in capacitance was $1.88 \mathrm{pF}$ with a standard deviation of 0.16 pF. Much of this scatter is due to the scatter in the measurement of the air capacitance: the $\mathrm{He}_{2} \mathrm{H}_{2}$ mix capacitance tended to be nearly constant at a given heat treating temperature varying on the average by less than $\pm 0.06 \mathrm{pF}$. The slope of the linear fit of the difference capacitance is on the order of $-10^{-4}$ $\mathrm{pF} /{ }^{\circ} \mathrm{C}$ which is nearly a horizontal line. Thus, although the capacitance shows the effects of heat treating, the difference between the air and $\mathrm{He}_{2} \mathrm{H}_{2}$ mix capacitance does not systematically change with heat treating.

The major conclusion from these studies is that the heat treating of a Pd-SiC diode at higher temperatures does not significantly change its ability to operate as a hydrogen sensor at $100^{\circ} \mathrm{C}$. The formation of the interfacial layers between the $\mathrm{Pd}$ and $\mathrm{SiC}$ (presumably palladium silicides) and annealing within the $\mathrm{SiC}$ that have occurred with heating have shifted the baseline capacitance and slope of the $1 / C^{2}$ vs $\mathrm{V}$ curves. However, the results of this work suggest that significant features of the diode's behavior such as the form of the $\mathrm{C}$-t curves, the difference between the air and $\mathrm{He} / \mathrm{H}_{2}$ mix capacitances, and the barrier height in the $\mathrm{He} / \mathrm{H}_{2}$ mix do not change significantly with heat treating. This point is important for the use of the diode as a sensor since it allows recalibration if necessary of the sensor after heating. Nonetheless, given the changes that have occurred to the diode with this limited heat treating, long term testing is necessary to evaluate whether the diode is suitable for applications which require operation over an extended period of time.

\section{Operation at $400^{\circ} \mathrm{C}$}

Demonstration of the diode capabilities at 400 ${ }^{\circ} \mathrm{C}$ was performed in several different ambients. Prior to this $400^{\circ} \mathrm{C}$ testing, the diode was heat treated as described in the previous section. The purpose of these studies was to demonstrate the diode capabilities to operate as a hydrogen or hydrocarbon sensor in higher temperature environments that are of interest to the aeronautics community.

The capacitive response of the diode to cycles of air followed by a $1000 \mathrm{ppm} \mathrm{H}_{2}$ in $\mathrm{N}_{2}$ mixture $\left(\mathrm{N}_{2} / \mathrm{H}_{2}\right.$ 
mix) is shown in Figure 6. Such a cycle has parallels to sensor operation when exposed to a periodic leak. The sensor is first exposed to air for 10 minutes and then $\mathrm{N}_{2} / \mathrm{H}_{2}$ mix for 20 minutes followed by air for 20 minutes for 3 cycles. The capacitance in air and the hydrogen mixture is seen to be stable within a cycle and repeatable over the three cycles. The response and recovery times are on the order of the time the chamber takes to reach steady state. The corresponding curves of $1 / \mathrm{C}^{2}$ vs $\mathrm{V}$ in air and in the $\mathrm{N}_{2} / \mathrm{H}_{2}$ mix (not shown) are displaced but parallel as in the $100^{\circ} \mathrm{C}$ measurements (Figure 3 ). This suggests that the sensing mechanism at the two temperatures is the same: a change in the $P d$ work function due to the presence of hydrogen. The difference in the corresponding barrier height as measured by $1 / \mathrm{C}^{2}$ $v s \mathrm{~V}$ in air and in the $\mathrm{N}_{2} / \mathrm{H}_{2}$ mis are on the order of several hundred millivolts. This implies that the signal produced by this MS system to low concentrations of hydrogen is easily large enough to be used in a MOSFET configuration or be observed by measuring the current.

The response of the sensor measured using the diode forward current is shown in Figure 7. The

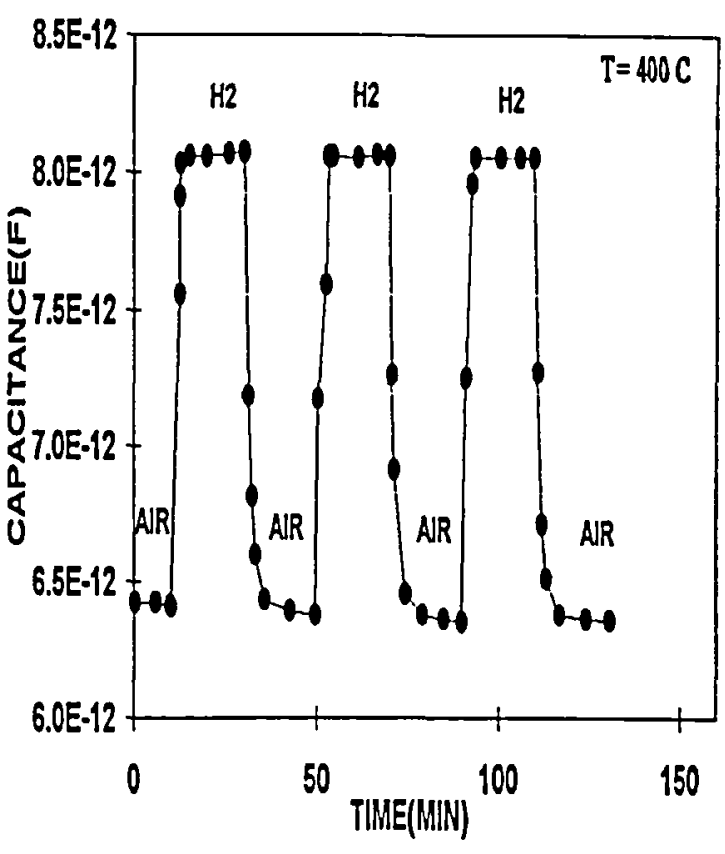

Figure 6. The capacitive response at zero bias of a Pd-SiC Schottky diode operated at $400{ }^{\circ} \mathrm{C}$ to cycles of air then $1000 \mathrm{ppm} \mathrm{H}_{2}$ in $\mathrm{N}_{2}$. The diode's response is significant and repeatable.

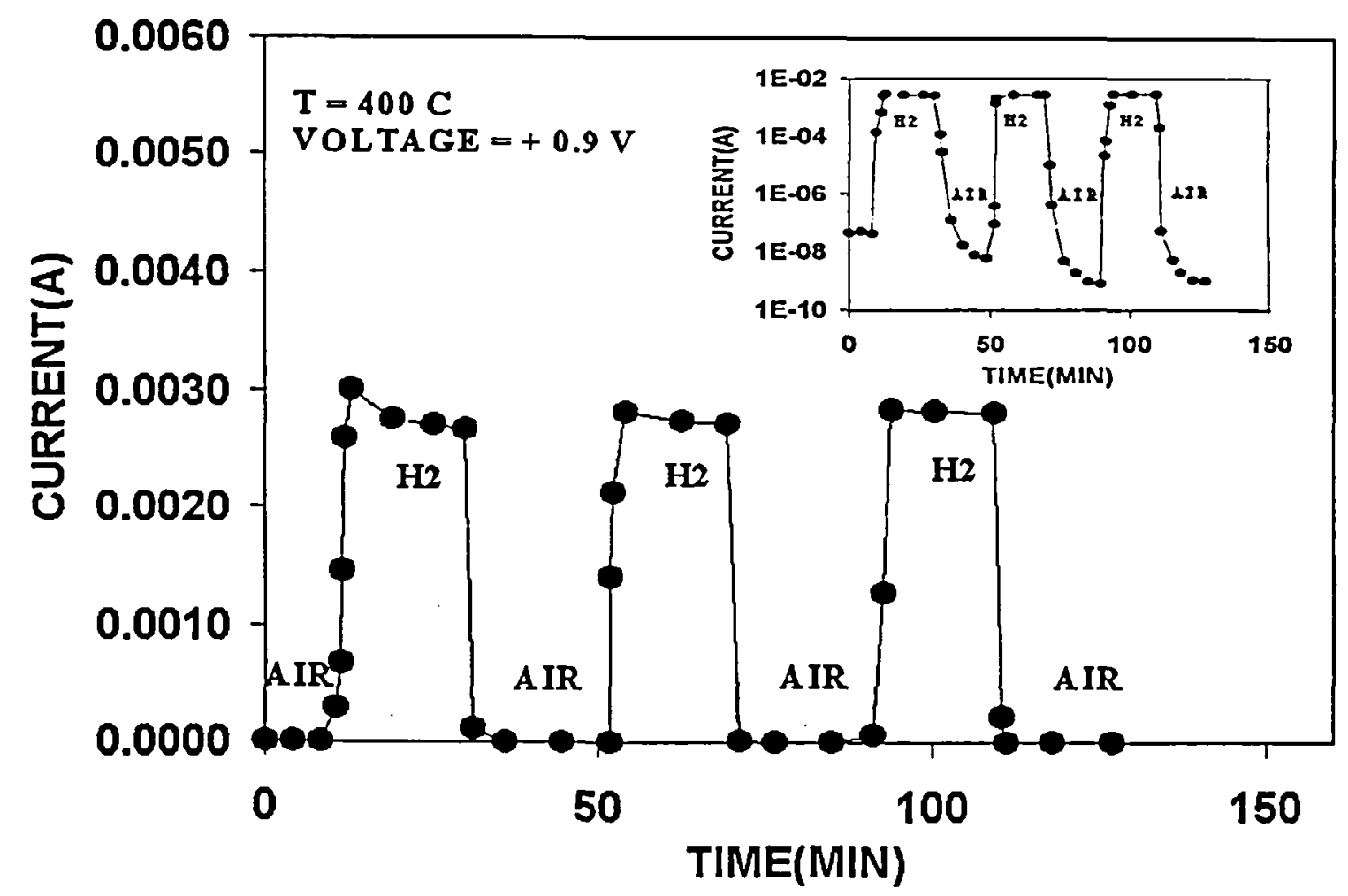

Figure 7. Response of the forward current at $+0.9 \mathrm{~V}$ of a Pd-SiC Schottky diode operated at $400 \mathrm{C}$ to 3 cycles of air followed by $1000 \mathrm{ppm}$ of $\mathrm{H}_{2}$ in $\mathrm{N}_{2}$. The inset shows the same data in a logarithmic scale. The diode forward current changes by more than a factor of 1000 upon exposure to $1000 \mathrm{ppm}$ hydrogen. 
sensor is biased at $+0.9 \mathrm{~V}$ and the forward current is measured as the diode is exposed to the same conditions as in Figure 6 . The inset of Figure 7 shows the same data as Figure 7 but in a logarithmic scale. The diode forward current in the $\mathrm{N}_{2} / \mathrm{H}_{2}$ mix is more than a factor of $\mathbf{1 0 0 0}$ larger than the baseline. During the first exposure in the $\mathrm{N}_{2} / \mathrm{H}_{2} \mathrm{mix}$, the diode current peaks before stabilizing. The magnitude of this peak is small when compared to the total change current. This is shown in the inset in which the peak is unobservable. Recovery of the diode current in air after exposure to the $\mathrm{N}_{2} / \mathrm{H}_{2}$ mix is rapid but the baseline current of the diode decreases with each cycle (see inset). This decrease in the baseline current is not reflected in diode response in the $\mathrm{N}_{2} / \mathrm{H}_{2}$ mix. The $\mathrm{N}_{2} / \mathrm{H}_{2}$ mix signal is stable and repeatable despite the baseline drift. These results show that the Pd-SiC Schottky diode has the potential of being a very sensitive hydrogen sensor.

The detection of hydrocarbons using the $\mathrm{Pd}-\mathrm{SiC}$ Schottky diode at $400^{\circ} \mathrm{C}$ is demonstrated in Figure 8 on a separate diode on the same $\mathrm{Pd}-\mathrm{SiC}$ chip. The diode is first exposed to air for $\mathbf{1 0}$ minutes, nitrogen for $\mathbf{4 0}$ minutes, followed by $\mathbf{3 0 0} \mathrm{ppm}$ of hydrogen in nitrogen and then $\mathbf{1 0}$ minutes of nitrogen and 10 minutes of air. The second and the third cycles are the same as the first except that the $300 \mathrm{ppm}$ of hydrogen is replaced by 300 ppm propylene in nitrogen, and then $300 \mathrm{ppm}$ of propylene in nitrogen and $1 \%$ oxygen respectively.

The response of the diode to hydrogen at $400^{\circ} \mathrm{C}$ in Figure 8 has several similarities to that at $100^{\circ} \mathrm{C}$ (Figure 2). In both cases, the capacitance increases slightly in an inert environment, increases significantly when exposed to $\mathrm{H}_{2}$, and has improved recovery in air to the baseline.

There are three points to note in Figure 8 with respect to hydrocarbon detection. First, and most importantly, the diode responds to propylene in $\mathrm{N}_{2}$ and in $\mathrm{N}_{2}+1 \% \mathrm{O}_{2}$. This demonstrates the diode's ability to measure hydrocarbons.

Second, the signal decreases as the mirture goes from hydrogen to propylene to propylene in oxygen. The proposed mechanism of hydrocarbon detection for the Pd on semiconductor systems is that the hydrocarbons dissociate on the Pd surface and hydrogen migrates into the Pd lattice. ${ }^{67}$ The hydrogen forms a dipole layer at the Pd-SiC interface which affects the electrical properties of the diode. The plot of $1 / C^{2} v s V$ in air (not shown) is displaced but parallel from those taken while the diode is in 300 ppm hydrogen in nitrogen and 300 ppm propylene in nitrogen. This suggests that the mechanism of detection is the same in both cases: a change in the work function of the Pd upon exposure to the gas. These results are consistent with the proposed mechanism of hydrocarbon detection. The reason for the smaller signal in propylene than in hydrogen may be due to incomplete dissociation of the hydrocarbon leading to less hydrogen available to migrate to the interface. Further, the presence of oxygen also decreases the amount of hydrogen available to go into the lattice. ${ }^{6}$ Thus, with even less hydrogen available to migrate to the interface than with propylene in nitrogen, the response decreases even further.

Finally, the baseline capacitance decreases after the exposure to propylene in nitrogen. The reason for this change and its repeatability is the subject for further investigations.

The major results from the characterization of the $\mathrm{Pd}-\mathrm{SiC}$ Schottky diode at $400^{\circ} \mathrm{C}$ are that the diode has been demonstrated as a sensitive hydrogen and hydrocarbon sensor. The results are consistent with the model that hydrogen and hydrocarbons dissociate at the surface and hydrogen migrates to the $\mathrm{Pd}-\mathrm{SiC}$ interface affecting the electronic properties of the diode.

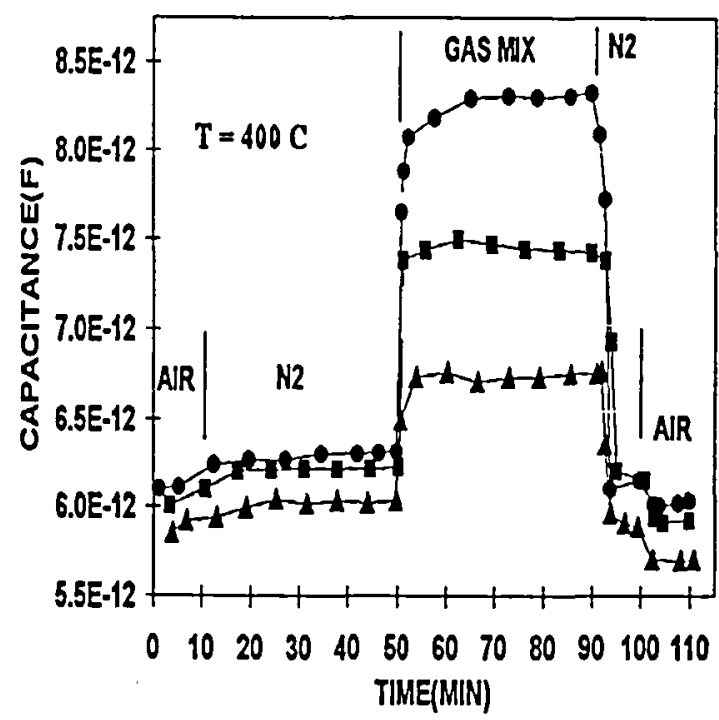

Figure 8. Capacitance vs time at $400^{\circ} \mathrm{C}$ upon exposure to nitrogen plus $300 \mathrm{ppm}$ of hydrogen (O) or propylene (I), or nitrogen plus 300 ppm propylene plus $1 \% \mathrm{O}_{2}(\Delta)$. The diode is first exposed to air, nitrogen then the hydrogen bearing gas mixture followed by nitrogen then air. 


\section{DEVELOPMENT OF A COMPLETE SENSOR PACKAGE}

Another component in the SiC sensor development program is the fabrication of a sensor package which will be able to accurately control the temperature of the sensing element. This effort is an attempt to transfer the previously developed Si-based hydrogen sensor technology ${ }^{1,12}$ to $\mathrm{SiC}$. The configuration of the Si-based CWRU structure is shown in Figure 9. The structure includes a Pd13\%Ag Schottky diode, $a$ temperature detector, and a heater all incorporated in the same chip. The sensor package may be mounted on a flat ceramic pack or in a TO5 header.

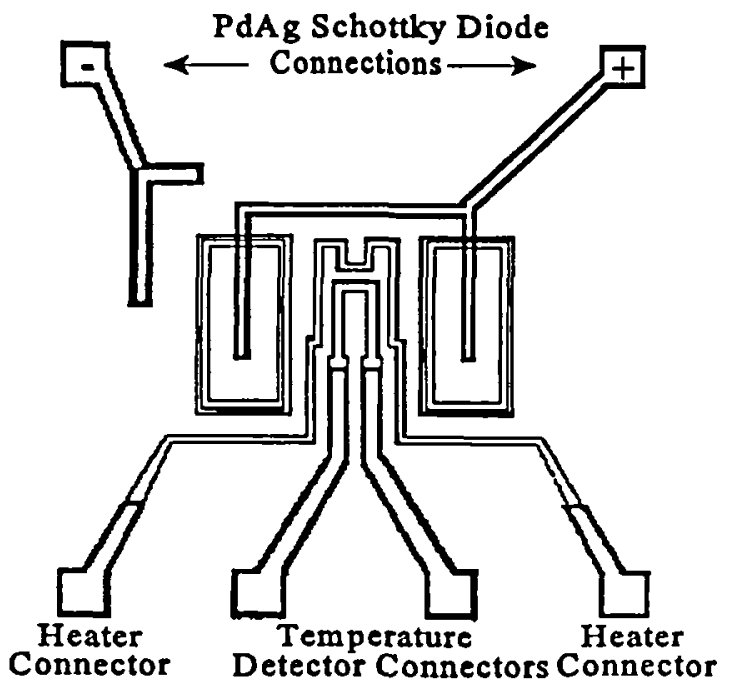

Figure 9. Schematic diagram of the Pd13\%Ag Schottky Diode Hydrogen Sensor. The Pd13\%Ag Schottky diode resides symmetrically on either side of a heater and temperature detector.

Modifications of this structure for high temperature applications are under way. For example, if the sensor is in a room temperature ambient, operation at high temperatures means that heat must be supplied to the sensor. Thus, the sensor heater must be modified to allow heating of the $\mathrm{SiC}$ sensors to much higher temperatures than presently available on the near room-temperature Si-based devices. Further, given the high thermal conductivity of $\mathrm{SiC}$ and the higher temperature operation, dissipation of heat from the sensor to the supporting ceramic pack or TO5 header is a problem. In an effort to minimize this heat dissipation, the sensor is not mounted directly onto the support.
Rather, the sensor will be suspended by its electrical connections above the support. Devices are presently being fabricated and will be tested in the near future.

\section{CONCLUSIONS AND FUTURE PLANS}

The characterization of Pd-SiC Schottky diodes at $100{ }^{\circ} \mathrm{C}$ and at $400^{\circ} \mathrm{C}$ demonstrates operation of the diode as a sensitive hydrogen sensor. Heat treatments up to $400^{\circ} \mathrm{C}$ do not disrupt the diode's ability to operate as a hydrogen sensor. The most obvious changes in the diode properties are in the baseline capacitance, slope of the $1 / C^{2}$ vs $V$ curves, and air barrier height after heating. However, the measured difference in capacitance between air and $\mathrm{He} / \mathrm{H}_{2}$ mix is nearly constant, and the barrier height as measured in the $\mathrm{He} / \mathrm{H}_{2}$ mix is statistically unchanged. Changes in the air barrier height after heating are recoverable after exposure to the $\mathrm{He} / \mathrm{H}_{2}$ mix.

Detection of hydrogen and hydrocarbons has been demonstrated at $400^{\circ} \mathrm{C}$. The hydrogen and hydrocarbon responses are consistent with a detection mechanism in which the hydrocarbons dissociate on the $\mathrm{Pd}$ surface resulting in $\mathrm{H}_{2}$ migration into the $\mathrm{Pd}$ and to the $\mathrm{Pd}-\mathrm{SiC}$ interface.

Continued development of SiC-based sensors is planned. Further studies will determine the long term stability of the sensor at high temperature. In particular, it will be determined if a barrier layer is necessary between the hydrogen sensitive metal and the $\mathrm{SiC}$ to stabilize the sensor structure. Further testing of the sensor in a variety of environments will be necessary to produce a complete sensor package for use in aeronautic and commercial applications.

\section{ACKNOWLEDGMENTS}

The authors would like to gratefully acknowledge the helpful discussions with Dr. W. D. Williams and W. C. Nieberding of NASA LeRC. The technical assistance of C. Salupo of Cortez/NASA LeRC is also acknowledged.

\section{REFERENCES}

1. Hunter, G. W.; Neudeck, P.G.; Liu, C.C.; and Wu, Q.H.: Advances in Hydrogen Sensor Technology for Aerospace Applications, 
presented at the 1994 Conference on Advanced Earth-To-Orbit Propulsion Technology, Marshall Space Center, Huntsville, AL, May 1994.

2. Hunter, G.W.; Neudeck, P.G.; Jefferson,G.D.; Madzsar, G.C.; Liu, C.C.; and Wu, Q.H.: The Development of Hydrogen Sensor Technology at NASA Lewis Research Center, Presented at the Fourth Annual Space System Health Management Technology Conference, Cincinnati, OH, Nov. 1992.

3. Arbab, A.; Spetz, A.; Wahab, Q.; Willander M.; and Lundstrom, I.: Chemical Sensors for High Temperatures Based on Silicon Carbide, Sensors and Materials, Vol. 4, No. 4, pp. 173-185, 1993.

4. Arbab, A.; Spetz, A.; and Lundstrom, I.: Gas Sensors for High Temperature Operation Based on Metal Oxide Silicon Carbide (MOSiC) Devices, Sensors and Actuators, Vol. B 15-16, pp. 19-23, 1993.

5. Karlsteen, M.; Spetz, A.; Arbab-Baranzahi, A.; Willander, M.; and Lundstrom, I.: "Electrical Properties of MIS Structures on 6H-SiC Measured at Temperatures from $300 \mathrm{~K}$ to 900K", Transactions of the Second International High Temperature Electronics Conference, Charlotte, NC, June 5-10, 1994.

6. Lundstrom, I.; Armgarth, M.; and Petersson, L.: Physics with Catalytic Metal Gate Chemical Sensors, CRC Critical Reviews in Solid State and Materials Sciences, Vol. 15, pp. 201$278,1989$.

7. Dannetun, H.; Lundstrom, I; and Petersson, L.G. : Hydrocarbon Dissociation on Palladium Studied with a Hydrogen Sensitive Pd-Metal-Oxide-Semiconductor Structure, J. Appl. Phys., Vol. 63, No. 1, pp. 207-215, 1988.

8. Powell, J. A.; Larkin, D. J.; Matus, L G.; Choyke, W. J.; Bradshaw, J. L; Henderson, L; Yoganathan, M.; Yang, J.; and Pirouz, P: Growth of High Quality 6H-SiC Epitaxial Films on Vicinal (0001) 6H-SiC Wafers, Appl. Phys. Lett., Vol. 56, pp. 1442-1444, 1990.

9. Cree Research Inc., 210 Meridian Parkway, Suite 176, Durham, NC 27713.
10. S. E. Sze, "Physics of Semiconductor Devices", Wiley-Interscience, New York (1969).

11. Bermudez, V.M.: Auger and Electron Energy-Loss Study of the Pd/SiC Interface and its Dependence on Oxidation, Applications of Surface Science, Vol. 17, pp. 12-22, 1983.

12. Hunter, Gary W.; Makel, D. B.; Jansa, E. D.; Patterson, G.; Cova, P. J.; Liu, C. C.; Wu, Q.H.; and Powers, W. T.: A Hydrogen Leak Detection System for Aerospace and Commercial Applications, To be Presented at the 31st AIAA Joint Propulsion Conference, San Diego, CA, July 10-12, 1995. 


\begin{tabular}{|c|c|c|c|}
\hline \multicolumn{3}{|c|}{ REPORT DOCUMENTATION PAGE } & $\begin{array}{l}\text { Form Approved } \\
\text { OMB No. 0704-0188 }\end{array}$ \\
\hline \multicolumn{4}{|c|}{ 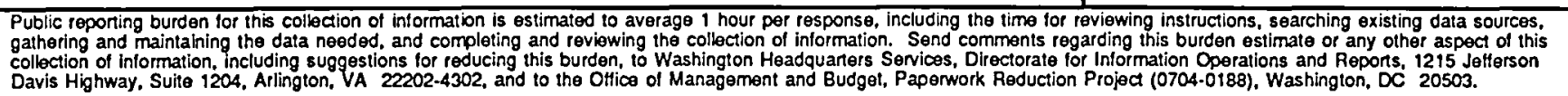 } \\
\hline 1. AGENCY USE ONLY (Leave blank) & $\begin{array}{r}\text { 2. REPORT DATE } \\
\text { October } 1995\end{array}$ & \multicolumn{2}{|c|}{$\begin{array}{l}\text { 3. REPORT TYPE ANO DATES COVERED } \\
\text { Technical Memorandum }\end{array}$} \\
\hline \multicolumn{3}{|c|}{$\begin{array}{l}\text { 4. TITLE AND SUBTTLE } \\
\text { Silicon Carbide-Based Hydrogen and Hydrocarbon Gas Detection }\end{array}$} & 5. FUNDING NUMBERS \\
\hline \multicolumn{3}{|c|}{$\begin{array}{l}\text { Gary W. Hunter, Philip G. Neudeck, Liang-Yu Chen, D. Knight, } \\
\text { C.C. Liu, and Q.H. Wu }\end{array}$} & WU-242-20-06 \\
\hline \multicolumn{3}{|c|}{$\begin{array}{l}\text { 7. PERFORMING ORGANIZATION NAME(S) AND ADDRESS(ES) } \\
\text { National Aeronautics and Space Administration } \\
\text { Lewis Research Center } \\
\text { Cleveland, Ohio } 44135-3191\end{array}$} & $\begin{array}{l}\text { FORMING ORGANIZATION } \\
\text { ORT NUMBER } \\
9925\end{array}$ \\
\hline \multicolumn{3}{|c|}{ 9. SPONSORING/MONITORING AGENCY NAME(S) AND ADDRESS(ES) } & $\begin{array}{l}\text { 10. SPONSORING/MONITORING } \\
\text { AGENCY REPORT NUMBER } \\
\text { NASA TM-107064 } \\
\text { AIAA-95-2647 }\end{array}$ \\
\hline \multicolumn{4}{|c|}{$\begin{array}{l}\text { 11. SUPPLEMENTARY NOTES } \\
\text { Prepared for the 31st Joint Propulsion Conference and Exhibit cosponsored by AIAA, ASME, SAE, and ASEE, San Diego, Califomia, } \\
\text { July 10-12, 1995. Gary W. Hunter, Philip G. Neudeck, and Liang-Yu Chen, NASA Lewis Research Center; D. Knight, Cortez III } \\
\text { Service Corporation, 21000 Brookpark Road, Cleveland, Ohio 44135; C.C. Liu and Q.H. Wu, Electronics Design Center, Case Western } \\
\text { Reserve University, Cleveland, Ohio 44106. Responsible person, Gary W. Hunter, organization code 2510, (216) 433-6459. }\end{array}$} \\
\hline \multicolumn{3}{|c|}{$\begin{array}{l}\text { 12a. DISTRIBUTIONAVAILABILTY STATEMENT } \\
\text { Unclassified - Unlimited } \\
\text { Subject Category } 35 \\
\text { This publication is available from the NASA Center for Aerospace Information, (301) 621-0390. }\end{array}$} & 12b. DISTRIBUTION CODE \\
\hline \multicolumn{4}{|c|}{$\begin{array}{l}\text { Hydrogen and hydrocarbon detection in aeronautical applications is important for reasons of safety and emissions control. } \\
\text { The use of silicon carbide as a semiconductor in a metal-semiconductor or metal-insulator-semiconductor structure opens } \\
\text { opportunities to measure hydrogen and hydrocarbons in high temperature environments beyond the capabilities of } \\
\text { silicon-based devices. The purpose of this paper is to explore the response and stability of Pd-SiC Schottky diodes as gas } \\
\text { sensors in the temperature range from } 100^{\circ} \mathrm{C} \text { to } 400^{\circ} \mathrm{C} \text {. The effect of heat treating on the diode properties as measured at } \\
100^{\circ} \mathrm{C} \text { is explored. Subsequent operation at } 400^{\circ} \mathrm{C} \text { demonstrates the diodes' sensitivity to hydrogen and hydrocarbons. } \\
\text { It is concluded that the Pd-SiC Schotuky diode has potential as a hydrogen and hydrocarbon sensor over a wide range of } \\
\text { temperatures but further studies are necessary to determine the diodes' long term stability. }\end{array}$} \\
\hline \multirow{2}{*}{\multicolumn{2}{|c|}{$\begin{array}{l}\text { 14. SUBJECT TERMS } \\
\text { Hydrogen; Hydrocarbon; Leak detection; Silicon carbide }\end{array}$}} & & 15. NUMBER OF PAGES \\
\hline & & & \begin{tabular}{|r|} 
16. PRICE CODE \\
A03
\end{tabular} \\
\hline $\begin{array}{l}\text { 17. SECURTY CLASSIFICATION } \\
\text { OF REPORT } \\
\text { Unclassified }\end{array}$ & $\begin{array}{l}\text { 18. SECURITY CLASSIFICATION } \\
\text { OF THIS PAGE } \\
\text { Unclassified }\end{array}$ & $\begin{array}{l}\text { 19. SECURITY CLASSIFICATIO } \\
\text { OF ABSTRACT } \\
\text { Unclassified }\end{array}$ & 20. LIMTATION OF ABSTRACT \\
\hline NSN 7540-01-280-5500 & & & $\begin{array}{l}\text { Indard Form } 298 \text { (Rev. 2-89) } \\
\text { scribed by ANSI SId. Z39-18 } \\
\text {-102 }\end{array}$ \\
\hline
\end{tabular}

